\title{
EDITORIAL
}

\section{Is fibromyalgia an autoimmune illness?}

\author{
Manuel Martínez-Lavín ${ }^{1}$ (D)
}

Received: 31 July 2021 / Revised: 8 August 2021 / Accepted: 10 August 2021 / Published online: 17 August 2021

(c) International League of Associations for Rheumatology (ILAR) 2021

\section{"Everything is autoimmune until proven otherwise" (Yehuda Shoenfeld)}

Fibromyalgia scientific knowledge has come a long way from the days when influential physicians viewed fibromyalgia as a "virtual disease" [1] and when fibromyalgia patients were considered "normal people whose individual personality traits and vulnerability predispose them to learning to lead a life of somatizing" [2]. Significant strides in fibromyalgia understanding have been gained in the last decade. The clear link between small fiber neuropathy and fibromyalgia [3] supports the long-standing, but neglected, proposal of fibromyalgia as a neuropathic pain syndrome $[4,5]$. Nowadays, skin biopsy and corneal confocal microscopy can objectively define the presence of small nerve fiber pathology in fibromyalgia individuals [3].

A recent meticulous investigation proposes autoimmunity at the epicenter of fibromyalgia pathogenesis. Goebel et al. describe mice injected with immunoglobulin $\mathrm{G}(\mathrm{IgG})$ from fibromyalgia patients developing hyperalgesia and peripheral small fiber denervation. Fibromyalgia patients IgG was exclusively accumulated in mice dorsal root ganglia (DRG). Among DRG components, satellite glial cells were the main IgG antigenic target [6]. With this new ground-breaking information, a key investigational issue emerges; is fibromyalgia a primarily autoimmune illness?

Autoimmune disease can be defined as "a pathologic state in which an aberrant immune response directed at a normal bodily constituent leads to inflammation, cell injury, or a functional disturbance with clinical manifestations." The molecular element (i.e., protein, carbohydrate, nucleic acid) that is targeted in autoimmunity is called an autoantigen. An autoimmune disease usually involves both a $\mathrm{T}$ and $\mathrm{B}$ cell response and can be generalized or tissue- or organ-specific [7].

Manuel Martínez-Lavín

drmartinezlavin@gmail.com

1 Chief Rheumatology Department, National Institute of Cardiology, Mexico City, Mexico
Fibromyalgia is clearly a stress-related disorder. Different psychological, physical, metabolic, infectious, and/or autoimmune stressors are frequent fibromyalgia drivers [8] Nevertheless, only a minority of fibromyalgia patients displays clinically recognizable autoimmunity and/or auto-antibodies. The stress-evoked neuropathic pain animal model is informative. In rodents, diverse physical [9] or environmental stressors [10] can lead to DRG phenotypic changes and to hyperalgesia.

Goebel et al.'s autoimmune findings can be reconciled with the proposal of fibromyalgia as a stress-related disorder. Stress-related biomolecules exert control over various cells in the innate and adaptive arms of the immune system. Stress has been linked to the onset and/or exacerbation of diverse autoimmune diseases [11].

DRG have a unique physio-anatomy. They contain the small nerve fiber nucleus tightly enveloped by immunologically active satellite glial cells and surrounded by different immune competent/pronociceptive mediators including macrophages and lymphocytes [12]. DRG can sequester antigenspecific antibodies [13]. Different stressors induce profound DRG phenotypic changes [9].

It can be postulated that in fibromyalgia, stress-evoked DRG molecular changes become antigenic. These neoantigens would induce localized antibody response leading to sensory nerve fiber inflammation, hyper-excitability, and peripheral denervation. DRG phenotypic changes can also explain fibromyalgia dysautonomia-related symptoms including chronic fatigue and irritable bowel. There is direct anatomical communication between DRG and the paravertebral sympathetic chain [14]. DRG mechanosensitive neurons projecting to distal blood vessels seem to play a major role in cardiovascular autonomic regulation [15]. Satellite glial cells not only encase DRG neuron cell bodies but also neurons lying in sympathetic and parasympathetic ganglia [16].

Goebel et al.'s provocative study supports our reiterated proposal of DRG as the key neural hub where different fibromyalgia-inducing stressors, including autoimmune illnesses, are converted into neuropathic pain $[14,17,18]$. 
More research is needed to define if fibromyalgia is a localized autoimmune illness. Auspiciously, we have now a novel coherent physio-pathological model to explain fibromyalgia elusive mechanisms. Accumulating evidence proposes DRG at the epicenter of fibromyalgia pain, and this is a clearly testable hypothesis. DRG culture has become a standard research tool. Cultured DRG would be able to identify the purported fibromyalgia antigen. This in vitro assay can be applied in studies using neural electrophysiology, signal transduction, neurotransmitter release, or imaging [19]. Theoretically, DRG culture may also help to design specific fibromyalgia therapeutic molecules directed to well-defined pronociceptive targets or antigenic epitopes.

We are transiting from an era of misogynistic disbelief of fibromyalgia structural underpinning to a time of innovative research based on well-structured scientific evidence.

\section{Compliance with ethical standards}

Disclosures None.

\section{References}

1. Ehrlich G (2003) Fibromyalgia, a virtual disease. Clin Rheumatol 22:8-11. https://doi.org/10.1007/s10067-002-0697-7

2. Hadler NM (1997) Fibromyalgia, chronic fatigue, and other iatrogenic diagnostic algorithms. Do some labels escalate illness in vulnerable patients? Postgrad Med 102. https://doi.org/10.3810/ pgm.1997.08.284

3. Martínez-Lavín M (2018) Fibromyalgia and small fiber neuropathy: the plot thickens! Clin Rheumatol 37(12):3167-3171. https:// doi.org/10.1007/s10067-018-4300-2

4. Martínez-Lavin M, López S, Medina M, Nava A (2003) Use of the Leeds assessment of neuropathic symptoms and signs questionnaire in patients with fibromyalgia. Semin Arthritis Rheum 32(6):407-411. https://doi.org/10.1053/sarh.2003.50017

5. Martinez-Lavin M (2006) Fibromyalgia is a neuropathic pain syndrome. J Rheumatol 33(4):827-828

6. Goebel A, Krock E, Gentry C, Israel MR, Jurczak A, Urbina CM, Sandor K, Vastani N, Maurer M, Cuhadar U, Sensi S, Nomura Y, Menezes J, Baharpoor A, Brieskorn L, Sandström A, Tour J, Kadetoff D, Haglund L, Kosek E, ..., Andersson DA (2021) Passive transfer of fibromyalgia symptoms from patients to mice. $\mathrm{J}$ Clin Investig 131(13):e144201https://doi.org/10.1172/JCI144201

7. Pisetsky David (2021) Overview on autoimmunity. In: Shur Peter $\mathrm{H}$ (ed) UpToDate. Waltham

8. Martinez-Lavin M (2007) Biology and therapy of fibromyalgia. Stress, the stress response system, and fibromyalgia. Arthritis Res Ther 9(4):216. https://doi.org/10.1186/ar2146
9. McLachlan EM, Hu P (2014) Inflammation in dorsal root ganglia after peripheral nerve injury: effects of the sympathetic innervation. Auton Neurosci 182:108-117. https://doi.org/10.1016/j. autneu.2013.12.009

10. Hung $\mathrm{CH}$, Lee $\mathrm{CH}$, Tsai $\mathrm{MH}$, Chen $\mathrm{CH}$, Lin HF, Hsu CY, Lai CL, Chen CC (2020) Activation of acid-sensing ion channel 3 by lysophosphatidylcholine 16:0 mediates psychological stress induced fibromyalgia-like pain. Ann Rheum Dis:annrheumdis2020-218329. https://doi.org/10.1136/annrh eumdis-2020-218329

11. Sharif K, Watad A, Coplan L, Lichtbroun B, Krosser A, Lichtbroun M, Bragazzi NL, Amital H, Afek A, Shoenfeld Y (2018) The role of stress in the mosaic of autoimmunity: An overlooked association. Autoimmun Rev 17(10):967-983. https://doi. org/10.1016/j.autrev.2018.04.005

12. Haberberger RV, Barry C, Dominguez N, Matusica D (2019) Human dorsal root ganglia. Front Cell Neurosci 13:271. https:// doi.org/10.3389/fncel.2019.00271

13. Gunasekaran M, Chatterjee PK, Shih A, Imperato GH, Addorisio M, Kumar G, Lee A, Graf JF, Meyer D, Marino M, Puleo C, Ashe J, Cox MA, Mak TW, Bouton C, Sherry B, Diamond B, Andersson U, Coleman TR, Metz CN, Tracey KJ, Chavan SS (2018) Immunization elicits antigen-specific antibody sequestration in dorsal root ganglia sensory neurons. Front Immunol 9:638

14. Martínez-Lavín M (2021) Dorsal root ganglia: fibromyalgia pain factory? Clin Rheumatol 40(2):783-787. https://doi.org/10.1007/ s10067-020-05528-z

15. Morelli C, Castaldi L, Brown SJ, Streich LL, Websdale A, Taberner FJ, Cerreti B, Barenghi A, Blum KM, Sawitzke J, Frank T, Steffens LK, Doleschall B, Serrao J, Ferrarini D, Lechner SG, Prevedel R, Heppenstall PA (2021) Identification of a population of peripheral sensory neurons that regulates blood pressure. Cell Rep 35(9):109191. https://doi.org/10.1016/j.celrep.2021.109191

16. Hanani M, Spray DC (2020) Emerging importance of satellite glia in nervous system function and dysfunction. Nat Rev Neurosci 21(9):485-498. https://doi.org/10.1038/s41583-020-0333-Z

17. Vargas-Alarcon G, Alvarez-Leon E, Fragoso JM, Vargas A, Martinez A, Vallejo M, Martinez-Lavin M (2012) A SCN9A gene-encoded dorsal root ganglia sodium channel polymorphism associated with severe fibromyalgia. BMC Musculoskelet Disord 13:23. https://doi.org/10.1186/1471-2474-13-23

18. Martinez-Lavin M, Solano C (2009) Dorsal root ganglia, sodium channels, and fibromyalgia sympathetic pain. Med Hypotheses 72(1):64-66. https://doi.org/10.1016/j.mehy.2008.07.055

19. Segura-Chama P, Luis E, Almanza A, Pellicer F, Hernández-Cruz A, Mercado F (2020) Modulation of intracellular calcium concentration by D2-like DA receptor agonists in non-peptidergic DRG neurons is mediated mainly by $\mathrm{D} 4$ receptor activation. Neurosci Lett 736:135267. https://doi.org/10.1016/j.neulet.2020.135267

Publisher's note Springer Nature remains neutral with regard to jurisdictional claims in published maps and institutional affiliations. 